\title{
DELEUZE Y LA NOVELA CORTA: LAS LÍNEAS DE VIDA EN EL ÚLTIMO PECADO
}

Jorge Francisco Maldonado Serrano Mario Palencia Silva Alonso Silva Rojas 


\title{
DELEUZE Y LA NOVELA CORTA: LAS LÍNEAS DE VIDA EN EL ÚLTIMO PECADO
}

\begin{abstract}
Resumen: El último pecado del escritor santandereano Juan Cristóbal Martínez se propone y muestra pertenecer al género novela y al subgénero novela corta. Para ello se acude a cinco diferentes propuestas teóricas: Forster, Pabs, Pavel, Lukács y Deleuze. Filiado su género y establecida su especial tipología, se pregunta desde las reflexiones filosófico literarias de Deleuze-Guattari, plasmadas en Mil mesetas y otras de sus obras, ¿cómo se muestra en El último pecado la especificidad de la novela corta, según la propuesta de Deleuze-Guattari? Se identifican sus rasgos, sus líneas, cruzamientos y rupturas y se propone una singular representación para esta novela de Martínez.
\end{abstract}

Palabras clave: Novela corta, Deleuze y la literatura, filosofía y literatura, líneas de fuga, rupturas.

\section{DELEUZE AND THE NOVEL: THE CROSSLINES IN THE EL ÚLTIMO PECADO}

\begin{abstract}
The El último pecado of the Santanderean writer Juan Cristóbal Martínez is proposed and shown to belong to the genus novella and subgenus novel. To do this, we resort to five different theoretical proposals: Foster, Pabs, Pavel, Lukács and Deleuze. Demonstrated the genre and established its special type, we ask, based on the philosophical and literacy considerations of Deleuze-Guattari, in Thousand Plateaus and reflected in other works, how is shown the specificity of the novel in $E I$ último pecado as proposed by Deleuze-Guattari? Its features, cross-lines and breaks are identified and a unique representation is proposed of Martínez's novel.
\end{abstract}

Keywords: Novel, Deleuze and literature, philosophy and literature, crosslines, breaks.

Fecha de recepción: abril 23 de 2014

Fecha de aceptación: julio 07 de 2014

Forma de citar: Maldonado, J.; Palencia, M. y Silva, A. (2015). "Deleuze y la novela corta: las líneas de vida en El último pecado". Revista Filosofía UIS. 14 (1). pp. 169-185.

Jorge Francisco Maldonado Serrano: colombiano. Profesor Escuela de Filosofía, Universidad Industrial de Santander.

Correo electrónico: jorgefcomaldonado@gmail.com

Mario Palencia Silva: colombiano. Profesor Escuela de Filosofía, Universidad Industrial de Santander.

Correo electrónico: palencia@uis.edu.co

Alonso Silva Rojas: colombiano. Profesor Escuela de Filosofía, Universidad Industrial de Santander.

Correo electrónico: asilvaster@gmail.com 


\section{DELEUZE Y LA NOVELA CORTA: LAS LÍNEAS DE VIDA EN EL ÚLTIMO PECADO}

En un libro, como en cualquier otra cosa, hay líneas de articulación o de segmentaridad, estratos, territorialidades; pero también líneas de fuga, movimiento de desterritorialización y de desestratificación. Las velocidades comparadas de flujo según esas líneas generan fenómenos de retraso relativo, de viscosidad, o, al contrario, de precipitación y de ruptura. Todo eso, las líneas y velocidades mesurables, constituye un agenciamiento (agencement). Un libro es precisamente un agenciamiento de ese tipo y, como tal, inatribuible. Un libro es una multiplicidad (Deleuze-Guattari, 2010, p. 9-10).

\section{Introducción}

Como es sabido, la novela corta constituye un género literario que se diferencia del cuento y la novela; sin embargo, persiste la pregunta por la determinación de sus características esenciales. Es así como, en este artículo, se traerán a colación algunos de los más importantes intentos de su definición, para arrivar a la propuesta desarrollada por Deleuze-Guattari, que servirá de base a la lectura filosófica de la novela corta El último pecado de Juan Cristóbal Martínez, escritor colombiano, nacido en Socorro, Santander. Se mostrará, a través de un ejercicio interpretativo concreto, cómo la propuesta deleuziana permite comprender filosóficamente la literatura. Para ello, fundados en el estudio de las tres triadas de líneas de vida que, según Deleuze-Guattari, se desenvuelven en la novela corta, se llevará a cabo un análisis de El último pecado, en el que se presentará cómo en ella sólo se desarrollan las dos primeras líneas de cada una de las triadas en cuestión, sin agenciarse la línea de fuga, propiamente. Esta última se frustra, en la medida en que su protagonista, debido a la fuerza ejercida sobre él por el edipo y la cultura, como supresores del deseo, se reterritorializa, en la máquina social de donde inicialmente se había podido desterritorializar. 
En este sentido, este trabajo: 1. Realizará una breve reseña de la génesis y caracterización de la novela corta como género. 2. Expondrá el concepto de novela corta en Deleuze que determina el sentido de la novela corta y establece las triádicas líneas de agenciamiento. 3. Efectuará una lectura de El último pecado con base en las líneas de vida por las que entra el protagonista de la narración.

\section{La novela corta: su génesis y caracterización}

¿Cuál es el diferencial de la novela corta? Nos aproximaremos a ella, en un primer momento, desde tres concepciones.

Como todos sabemos, gracias al trabajo clásico del profesor Walter Pabst, en su trabajo La novela corta en la teoría y en la creación literaria (1972), la novela corta fue otra de las tareas que la cultura griega parece habernos dejado adelantada. Las raíces de su historia se hunden en los clásicos tiempos y géneros griegos. Género que, entre otras cosas, no fue objeto de estudio en la Poética aristotélica. Pabst nos entrega una cuidadosa historia de su génesis y evolución, de sus enmascaramientos, durante otros tiempos y espacios, en géneros literarios considerados menores.

Por otra parte, algunos teóricos, como Kurt Spang, en Géneros literarios (1993), afirma que la novela corta aparece, la mayoría de las veces, enmascarada de "exemplas", de cuentos, de florecillas, de biografías — reales o ficticias - con un fortísimo andamiaje lúdico. De esta forma, logró atravesar y salir enriquecida de la dura persecución de la cual la hicieran víctima, por ejemplo, en los oscuros tiempos medievales. En efecto, en esta época, su ropaje fue frecuentemente el humor, que le serviría, no solamente para distraer, sino para enunciar, bajo el ropaje del loco, andariego y pobre trovador o cantor, algunas verdades. Perseguida y asediada, parte de la verdad vino a encontrar un vehículo de expresión en este género. Así, durante su trasegar nómada se fue fortaleciendo para reaparecer en el marco del Renacimiento y salir a la superficie en la estética romántica.

Pabst aclarará que:

Así, de los proemios y los préfaces puede deducirse toda una doctrina de la novela corta que, en el fondo, no es más que una réplica refinada o irónica de la creación literaria a las voces de mundo de la crítica [...] La pregunta relativa a desde cuándo existe la novela corta en sentido lato apenas sí podrá ser respondida de forma satisfactoria. Todos los indicios parecen indicar que la novelística corta de la que poseemos testimonios literarios hubo de estar precedida de otra anterior medieval, no escrita o cuando menos desaparecida, que encerraba ya en sí todas las posibilidades del desarrollo artístico (Pabst, 1972, p.18-19). 
A la pregunta por la génesis de la novela corta, por su refundición y enmascaramiento en otros géneros y a su deslindamiento y especificidad, parece darle parcial respuesta Thomas Pavel, en Representar la Existencia. En este estudio, Pavel, interesado por el contenido, la forma, la estructura y la concepción de mundo de la novela corta, responde, pasajeramente, al tema de la génesis de este género. Para Pavel:

El relato elegíaco y la novela corta, dos géneros con una larga tradición que tienen como objeto la imperfección humana, también subordinan las situaciones presentadas a una idea claramente concebida, la de la vanidad del amor, por ejemplo, o la del peligro representado por la curiosidad excesiva. Esta idea, cuyo alcance es limitado, se revela en la individualidad de un caso sorprendente (2005, p.104).

En este contexto interpretativo, Pavel propone, entonces, filiar el origen de la novela corta al relato elegíaco. Pavel, además, agregará algunas importantes líneas de aclaración histórica y constitutiva del tópico que aquí seguimos: "La novela corta, género cuyo pasado oral es inmediatamente perceptible para el investigador que se asoma al vasto catálogo morfológico de los cuentos populares establecidos por Anti Aarne y completado por Stith Thompson, florece en Italia, Francia y España durante los siglos XIV a XVII" (105).

Podemos entonces, como síntesis, llegar a una primera conclusión: La novela corta hunde sus profundas raíces en la cultura griega clásica y, aunque oculta y trasvertida en otros géneros como relatos alegóricos, biográficos reales o ficticios y "exempla", tiene un resurgir determinante en los marcos de la cultura renacentista para, desde allí, y clasificada su especialidad, hacer carrera con los otros géneros literarios: Novela, cuento, tragedia, comedia, etc. ${ }^{1}$

\footnotetext{
${ }^{1}$ Ahora bien, es interesante anotar, en este contexto, que en el caso colombiano, la novela corta no cuenta con suficientes estudios detallados sobre sus líneas de constitución y devenir esencial. Sea ésta una queja del vacío que hemos dejado en la historia de nuestras letras. Como sabemos, y para nuestra fortuna, aún quedan muchas tareas sin hacer. No es este el caso para las letras, y para el género en el departamento de Santander, pues acerca de la novela corta, para esta región, podemos responder con alguna precisión: la novela corta tiene sus primeras manifestaciones con las letras santandereanas. Como todos sabemos, Santander es reconocido departamento en 1859. En 1860 se escribe ahí la primera novela, a saber, Una tarde de verano. Tres años después aparecerá la novela Resignación. Las dos son de la autoría de Daniel Mantilla Orbegoso. Estas dos piezas fundacionales de la literatura santandereana son novelas cortas, afirmación que deberemos mostrar, con mayor detenimiento y precisión, en otro momento y lugar. En la historia del género, en Santander, volveremos a vérnoslas con la novela corta, en la segunda década del siglo XX. Allí, mediante el proyecto cultural, intelectual y editorial, auspiciado por Antonio María Sepúlveda, que llevaría por título: La novela breve; se publicaron más de ocho números (según informes de la época). Precisamente, en uno de ellos, hará su aparición, en Bucaramanga, la novela de la que trataremos en esta oportunidad: El último pecado. Otras novelas cortas de interés, publicadas en el marco de este proyecto editorial son: Entre nosotros, de don Antonio M. Sepúlveda y Misia Paca (novela mística) de Blas Hernández. Tenemos, entonces, que la
} 
Otros autores, incluido Deleuze, no parecen interesarse por este problema histórico-genético. Así, por ejemplo, en sus Aspectos de la Novela, Sir Edward Morgan Forster no responderá a esta cuestión y lo mismo hará Georg Lukács en EI alma y las formas y Teoría de la novela.

Es importante señalar que Sir Edward Morgan Forster propuso, en Aspectos de la novela, un criterio cuantitativo de clasificación de la novela corta. Así, para el escritor, debía tenerse como novela corta a todo relato que se situara entre las treinta y cinco mil palabras y las cincuenta mil. Este criterio de clasificación es válido, pero deja un espacio demasiado amplio para la crítica, en cuanto no clarifica preguntas importantes como las siguientes: ¿qué es?, ¿por qué un objeto puede y debe ser leído y reconocido como novela corta?, ¿qué hay en él, más allá del limpio y sencillo criterio de su extensión, que así lo determine? Preguntas centrales en el ejercicio de reflexión que aquí proponemos.

Otros estudiosos del problema de la novela corta, que han realizado intentos de definición y de precisión acerca de su contenido, su forma y su estructura (intentos de pensamiento provenientes, además, de distintas corrientes críticas, literarias, teórico-literarias y teórico-filosóficas), han manifestado una compleja y rica variedad de posibilidades de este género literario que han esclarecido en algo el problema, pero también han contribuido enormemente a su confusión.

Así, por ejemplo, puede verse cómo la mayoría de los autores empeñados en algún tipo de resolución de los problemas relacionados con la novela corta, bien sean sobre su origen, su temática, su evolución o su contenido, suelen proceder por el recurso analógico al entablar un diálogo dilucidante, entre el objeto, la novela corta, y sus más cercanos parientes narrativo-literarios mayores y menores: la novela y el cuento. Pero no siempre es así, y Georg Lukács, en El alma y las formas y Teoría de la novela, nos sorprenderá al establecer la analogía entre la novela corta y la tragedia.

enciclopedia de la novela corta, para Santander, se sitúa, numéricamente, entre los diez y los doce títulos, aproximadamente; lo que es, desde ya, una alta cifra del género, si se considera que la novela en este departamento, cuenta con un número cercano a los ciento sesenta títulos.

Ahora bien, esta lectura estadística no responde por la diversidad de las filiaciones estéticas, de visiones de mundo, de corrientes, o de tendencias de la novela en Santander. Otras focalizaciones nos obligarán a pensar a la novela como: La novela histórica, la novela policiaca, la novela telúrica, la novela de la violencia o novela romántica, modernista, realista (de varios realismos), novela social, etc. Y muy seguramente, la novela corta deberá saber situarse en cada una de estas distintas opciones. Por ahora, bástenos señalar que la novela corta, en el departamento de Santander, se ha escrito y tiene registros en las distintas estéticas, en las distintas tendencias; como por ejemplo, la novela del homosexual, de la cual es fundadora El último pecado, para la región y sospechamos que para las letras nacionales. 
En efecto, Lukács abordará el problema en el capítulo "El instante y las formas (Richard Beer-Hofmann)" en el que el eje temático de su reflexión lo constituye un rasgo del género trágico moderno: la idea y el tratamiento del tiempo en la tragedia. Allí, entre múltiples relaciones de complementación y oposición, pueden leerse algunos datos, luminosos para la reflexión e intento de definición del género que aquí nos convoca. Por ejemplo, afirma Lukács: "En el caso de las novelas cortas esto significaría que una situación puesta como irresoluble, ha sido de todos modos resuelta; la novela corta da en su contenido una sorpresa (precisamente por el procedimiento de desdibujar la sorpresa en la forma) [...] El contenido de las novelas cortas es el desarrollo de un ser humano a consecuencia de una catástrofe casual" (Lukács, 1985, p. 190).

Otros apuntes, de particular interés, aparecerán constantemente en Lukács, pero quedemos, por el momento, con este dato singular, pues parece ser el único teórico (filósofo) que relaciona directamente a la novela corta con la tragedia.

Por su parte, Thomas Pavel, autor que ya hemos referido en estas páginas, sigue la idea de una evolución y enmascaramiento de la novela corta en otros géneros menores. Pavel vuelve sobre la analogía narrativa con géneros mayores y menores; es decir, con la novela, el cuento, las "exempla", etc.

Pero Pavel nos otorgará una visión de novela corta que incrusta una importantísima característica para el género, rasgo ya señalado por Lukács y que será determinante en la definición deleuziana: la idea de ruptura de una secuencia, la idea de fragmentación de una linealidad, de cualquier tipo, y la idea de un secreto, de una imposibilidad por llegar a saber: ¿qué ha pasado?, ¿qué ocasionó la ruptura, el retorno o la salida del trajinar constantemente por un determinado rumbo de una vida colectiva o individual?

Oigamos a Pavel y recordemos esta cita en la medida en que ecos de ella, pueden o deben oírse en la filosófica conceptualización que del género nos entregue Deleuze. Pavel nos dice que:

La novela corta se consagra, como en la novela picaresca, al estudio de la imperfección humana ${ }^{2}$, pero en lugar de presentarla como una hipótesis general que trata de enumerar pacientemente la multiplicidad de las consecuencias, se dedica a un único aspecto de la imperfección, que se revela de forma sorprendente en medio de la acción. Su objeto principal es la separación entre el individuo y su medio, concebida no como un dato abstracto inicial, sino como el resultado lógico del comportamiento del protagonista, que se ve expulsado de su medio o bien se aparta de él de manera más o menos voluntaria (Pavel, 2005, p.105).

${ }^{2}$ El subrayado es nuestro. 
Pavel nos aclara, además, lo siguiente:

Pero en la mayoría de los casos la exclusión del seno de la comunidad representa la consecuencia o el castigo bien merecido de una transgresión cometida por el protagonista. Pero aunque terminan rechazados por su medio, el inicio de la acción muestra a los personajes de la novela corta bien integrados en éste, sin que nada haga presagiar la inversión ulterior de su destino. Ello explica que la novela corta subraye los vínculos de los protagonistas con su familia y su ciudad y, en consecuencia, se interese por la inserción social e histórica de sus personajes. Esta inserción suele estar representada (no de forma única) por el matrimonio, y la falta que acaba provocando el desequilibrio es la seducción amorosa fuera de los límites conyugales (105-106).

Queda, entonces, planteado el asunto que nos interesa resaltar de la novela corta, a saber, la compleja relación que ella supone entre los protagonistas y los agenciamientos sociales y vitales dentro de los cuales ellos realizan su existencia. Esta será la línea de flujo que nos conduce a Deleuze.

\section{Deleuze y la novela corta}

Oigamos ahora a Deleuze, de quien estimamos procede y permanece la mejor opción de definición, caracterización y tipología de la novela corta. Sus planteamientos al respecto los encontramos, entre otras páginas, principalmente en la meseta "1874. Tres novelas cortas, o '¿Qué ha pasado?'”, recogido en Mil Mesetas (2010). Deleuze, como siempre, nos sumergirá en una densidad conceptual, de la cual viene él mismo a librarnos, gracias a la claridad de sus ejemplos. Y, como ya es su estilo, nos sitúa, sin efectos circunloquiales de preparación, frente y en el centro del problema: "No es difícil determinar la esencia de la novela corta como género literario: estamos ante una novela corta cuando todo está organizado en torno a la pregunta, "¿Qué ha pasado? ¿Qué ha podido pasar?" (Deleuze y Guattari, 2010, p. 197).

En el marco de estas preguntas, Deleuze estudiará en micro detalle, la analogía propuesta entre la novela corta, el cuento y la novela. Algunos de esos detalles que signan las diferencias genéricas pueden ser: el tiempo, el tratamiento del tiempo, la noción del tiempo y su sistema de relaciones, en las distintas manifestaciones genéricas. De esta manera, expone el filósofo:

Algo ha pasado, o algo va a pasar, pueden designar perfectamente un pasado tan inmediato, un futuro tan próximo, que se confunden (diría Husserl) con las retenciones y las protenciones del propio presente. Aún así, su distinción sigue siendo legítima, en nombre de los diferentes movimientos que animan, el presente, que son contemporáneos del presente, uno moviéndose con él, otro relegándolo ya al pasado, desde el momento en que es presente (novela corta), y otro arrastrándolo hacia el futuro al mismo tiempo (cuento) (198). 
Deleuze continúa tanto con la analogía cuento-novela corta, como con aquello que llega a ser sustancia de uno y otro género. Ahora bien, insistirá en un determinante tópico diferenciador de una y otra expresión. Se trata del grado de conocimiento que alcanzaría el lector en cada uno de estos géneros. Conocimiento relacionado con el acontecimiento que hizo entrar en un devenir a una vida social o individual: "Nunca se sabrá lo que acaba de pasar, siempre se sabrá lo que va a pasar, esas son las dos incertidumbres en las que se encontrará el lector frente a la novela corta y el cuento, y que son las dos maneras en las que se divide en cada instante el presente viviente" (198). Este ocultamiento, este hacer secreto, este velar el acontecimiento están anclados en lo profundo de la idea deleuziana de la incertidumbre propia de la novela corta, nunca se sabrá lo que acaba de pasar; esta sentencia que establece la sustancia del género, coincide con aquella feliz caracterización luckasiana del hacerse forma, en la novela corta, de aquello que nos sorprende: de ese ocultarse mediante la forma, propia de la sorpresa, anunciada como rasgo de la novela corta. Así tenemos, entonces, que, en la novela corta, "algo ha pasado, pero iqué exactamente?" (198).

Deleuze continúa con otras precisiones, a saber, las diferencias entre el cuento y la novela corta para, mediante ellos, presentar lo que la novela corta puede ser en su concepción filosófica. Así, afirma:

La novela corta está relacionada fundamentalmente con un secreto (no con una materia o con un objeto del secreto que habría que descubrir, sino con la forma del secreto que permanece inaccesible) mientras que el cuento está relacionado con el descubrimiento (la forma del descubrimiento, independientemente de lo que se pueda descubrir). Y también la novela corta pone en escena posturas del cuerpo y del espíritu, que son como pliegues y envolturas, mientras que el cuento pone en juego actitudes, posiciones, que son despliegues y desarrollos, incluso los más inesperados (198-199).

Luego de este esfuerzo relacional afirma, entonces, el filósofo, que la novela corta trata de posturas, de una modalidad o expresión y de un secreto: "La postura es como un suspenso invertido. No se trata, pues, de remitir la novela corta al pasado, y el cuento al futuro, sino de decir que la novela corta remite en el propio presente a la dimensión formal de algo que ha pasado, incluso si ese algo no es nada o permanece incognoscible" (199). De esta manera, se especifica el encadenamiento de la novela corta, de la siguiente manera: "¿Qué ha pasado? (modalidad o expresión), Secreto (forma), Postura del cuerpo (contenido)" (199).

Ahora bien, como la novela corta trata de una materia universal, de acuerdo al encademaniemto anterior, referida a nuestras hechuras vitales, y nosotros «estamos hechos de líneas», estas últimas han de ser empleadas por el filósofo para proponer diferentes relaciones triádicas de la novela corta, misma que hemos de 
seguir para interpretar El último pecado. Afirma, en efecto Deleuze: "[...] la novela corta se define en función de líneas vivientes, líneas de carne que ella revela de forma muy especial"(199).

La multiplicidad, la variedad de las líneas que nos constituyen no cesan su entrecruzamiento, produciendo constantemente cruces, choques, fisuras, fugas, fragmentaciones, reencuentros y dispersiones. No se trata sólo de líneas en el sentido escritural donde la línea del texto escrito se presenta como la articulación en el lenguaje de una realidad vivida, como pensará Taylor (1996). Las líneas de la vida son las líneas en las que se despliega la vida, la vida como una línea que, en tanto que continuum, no puede detenerse. La vida no para, como lo es por definición una línea. Si bien puede abstractamente cortarse en un punto inicial y final, realmente la vida se proyecta infinitamente en dos sentidos, cuestión que ya había desarrollado Deleuze en Lógica del sentido (1998), al postular que el sentido siempre es como mínimo doble.

No obstante, se hace necesario formular un mínimo posible de estas líneas y del variopinto juego de entrelazamientos y disoluciones que ellos posibilitan. Así, Deleuze estudiará y presentará varios de ellos y nos arrojará a su comprensión mediante la ejemplar lectura de sus manifestaciones en tres obras maestras de la novela corta:

a. En la primera manifestación (Dans la cage, de Henry James) encontramos tres líneas de vida: la línea de segmentariedad dura o molar — en cada uno de nosotros hay esta línea "[...] en la que todo parece medible y previsto, el principio y el final de un segmento, el paso de un segmento al otro (Deleuze y Guattari, 2010, p. 200)_; una línea de segmentación flexible o molecular — "en la que los segmentos son como cuantos de desterritorialización [y] [...] define un presente cuya forma es la de algo que ha pasado" —; y, finalmente, una especie de línea de fuga generada a partir del acontecimiento ocurrido en la segunda línea y que se define de la siguiente manera: "nada ha pasado [...] Y, sin embargo, todo ha cambiado" (201). Es decir, que esta línea "[...] ya no admite en modo alguno segmentos, y [...] es más bien como una explosión de las dos series segmentarias. Ha traspasado la pared, ha salido de los agujeros negros. Ha alcanzado una especie de desterritorialización absoluta" (201).

b. La segunda manifestación (The Crack up, de Fitzgerald) se compone de tres líneas: la línea de corte - "la vida no cesa de aventurarse por una segmentaridad cada vez más dura y reseca [...] el envejecimiento que sobre codifica todo lo que sucede" (202-203)—; la línea de fisura — que se produce de forma casi imperceptible, casi sin que uno se dé cuenta, microfisuras sutiles y flexibles-; y, la línea de ruptura _ " "....] que señala la explosión de las otras dos, su choque" (203)_, en cuanto el pasado deja de existir y lo que se rompe es irrecomponible. 
c. En la tercera manifestación (Historia del abismo y de la lente, de Pierrette Fleutiaux) tenemos también tres líneas, a saber: la de los «mirones de corto alcance», con lente simple que ven sólo "[...] el contorno de células gigantes, de grandes divisiones binarias, dicotomías, segmentos a su vez bien determinados [...]" (204), como el aula o el cuartel; la de los «mirones de largo alcance», quienes con una lente fina y compleja, "[...] ven toda una mocrosegmentaridad, detalles de detalles [...] es inseparable de la segmentación anónima que la produce, y que lo pone todo constantemente en tela de juicio, sin finalidad y sin razón"; y, los mirones de largo alcance que, un día (¿qué habrá pasado?) abandonan su segmento "[...] y se aventurará por una estrecha pasarela sobre el negro abismo [...]" (206).

Esta triada compone, de esta manera, un eje de posibilidades de mezcla interlineal que puede desembocar en múltiples combinaciones de vidas posibles. Por ello no hay una sola manera de interrelacionar la secuencia, ni de experimentar la línea de fuga, que es lo que importa. Para Deleuze, finalmente, queda una cosa: "[...] debemos inventar nuestras líneas de fuga si es que somos capaces de ello, y sólo podemos inventarlas trazándolas efectivamente, en la vida" (206).

\section{El último pecado: una lectura deleuziana}

A partir de estas ideas deleuzianas y de los otros teóricos aquí convocados intentaremos responder a la pregunta por el texto narrativo: El último pecado ${ }^{3}$ para mostrar como en ella se combinan las triadas de una novela corta, en los términos filosóficos propuestos por Deleuze.

\footnotetext{
La novela corta: El último pecado, de Juan Cristóbal Martínez, trata la historia de un joven, quien traicionado en amores por su novia, con quien pretendía casarse, decide romper con todos los compromisos adquiridos con ella y alejarse de su espacio de vivienda e irse, lo más lejos posible, de Elvira, sus amistades, sus costumbres y su familia.

Para ello, parte de Bucaramanga hacia Bogotá, lugar en el que conocerá nuevas amistades y tendrá nuevas experiencias que le permitirán, entre otras, olvidar a Elvira y su traición y, de paso, cobrar algo de venganza por la traición inesperada. Conocerá, entonces, a Mario, joven de una belleza muy cercana a su amor traidor y se insinuará una relación amorosa entre estos. De igual manera, errará por los caminos de la vida nocturna y sus ofertas de lujuria y derroche. En estos ambientes se encontrará con una actriz que le mostrará caminos no recorridos en su juventud y le propondrá experiencias muy desconocidas por él. En su intento por olvidar, siempre estará presente la imagen, las palabras y los consejos de su madre que le ata al pasado y que serán, en última instancia, los que le impidan echarse a rodar por los caminos de "la perdición" para renunciar a esta experiencia y volver, luego de destruir toda causa de este escape: libros, cuadros, amistades, etc. y , tras perdonar a Elvira, a reconciliarse con su pasado y proyectar una vida, un hogar simple y tranquilo frente a la capilla de su residencia, en la que transcurrió su infancia y su juventud.
} 
En primerísimo lugar acudiremos a una de las hipótesis, ya expuestas brevemente aquí, la enunciada por Edward Morgan Forster en sus Aspectos de la novela y que privilegió el criterio cuantitativo léxico. En dicha hipótesis se señala como criterio relevante los números entre 35.000 y 50.000 palabras. Si seguimos dicho criterio la duda desaparece y nuestro objeto debería ser reconocido como novela corta. Pero como ya hemos anticipado, esta hipótesis es muy poco confiable y de muy sencilla opción de rebatir. Dejemos también de lado las otras ideas, complementarias de esta hipótesis, expuestas por el mismo autor. Son aquellas que limitan el tiempo, el espacio, el número de personajes y la necesaria concentración y aprovechamiento, al máximo, de la calidad poética-polisémica de la palabra, por el género.

Por otro lado, es posible aplicar la idea central de la hipótesis de Pavel a EI último pecado y definirla como novela corta. Se trata, en efecto, de la consagración de la novela corta (como contenido) al estudio de la imperfección humana, su concentración a un único aspecto de dicha imperfección, y a que el objeto principal de la novela corta lo constituye la separación entre el individuo y su medio; concebida dicha separación como "el resultado lógico del comportamiento del protagonista", que se ve expulsado de su medio o bien se aparta de él de manera más o menos voluntaria" (Pavel, 2005, p. 105). Si acogemos esta definición, dada por Pavel, nuevamente El último pecado deberá ser reconocida como una novela corta, pues trata, efectivamente, de la separación, de la "ruptura" de un individuo de su colectividad y el respectivo retorno al redil, luego de su auto redención en la Tierra de Nod.

En efecto, César, el personaje central de la novela, ha decidido separarse, no sólo de su familia y de su grupo social, sino de su ciudad. Por eso, lo vemos residir en Bogotá. La separación ha sido motivada por la traición de su prometida "Laura", quien ya fue de otro hombre y César parece no estar dispuesto a aceptarla en compromiso perpetuo, por y en esa mácula. He allí la primera sorpresa y la primera fisura de un mundo rígido o aparentemente rígido que exhibe sus quiebres axiológicos, obligado a lanzarse al mundo para vengar una afrenta. César buscará refugio en un universo voluptuoso, en que rigen otras normas más flexibles, donde éstas sean permitidas. Nada mejor que unas relaciones 'no permitidas', prohibidas, como son las relaciones homosexuales, o las relaciones bisexuales indiscriminadas.

Lo que César ignora y llegará a saber, tras el cruce de este umbral, en el que «verdaderamente» él no es y no puede ser un habitante de la flexibilidad, es que deberá reconocerse como un individuo que sólo puede llegar a vivir la vida cuando ésta está regida por los imperios normativo-sociales, sexuales, culturales, etc., de su espacio-tiempo tradicional. Único lugar, línea dura donde no tendrá las tensiones que le provocan los márgenes de la normatividad. César llegará a redimir y a reencauzar su experimento de fuga con el retorno al segmento duro del cual ha pretendido escapar. 
Su salida hacia y en la vida marginal, le han permitido reconocerse como miembro de una colectividad, en la cual la experiencia y la vida dentro de la norma determina las posibilidades de existencia de los seres.

Para no agobiar a los lectores con todos y cada uno de los distintos teóricos aquí referidos, permítasenos apuntar que la lectura, en confrontación, de El último Pecado y las otras teorías nos ratifican que ésta es, en efecto, una novela corta.

De esta manera llegamos a nuestro punto de llegada en la reflexión, a saber: por qué, desde la teoría deleuziana para la novela corta, El último Pecado responde positivamente a esta determinación y es rica de comprensión respecto a las triadas señaladas por el filósofo para este género.

Antes de iniciar este análisis es importante señalar que el ejercicio aquí desarrollado se ha realizado en concordancia con lo expuesto por Deleuze, al delinear lo que él entiende por «esquizoanálisis», a saber:

El esquizoanálisis no tiene por objeto elementos ni conjuntos, ni sujetos, relaciones y estructuras. Tiene por objeto lineamientos, que atraviesan tanto a grupos como a individuos. Análisis del deseo, el esquizoanálisis es inmediatamente práctico, inmediatamente político, ya se trata de un individuo, de un grupo o de una sociedad. Pues, antes que el ser, está la política. La práctica no es posterior al establecimiento de los términos y de sus relaciones, sino que participa activamente en el trazado de las líneas, afronta los mismos peligros y las mismas variaciones de ellas. El esquizoanálisis $[. .$.$] no tiene ningún problema de aplicación: aísla líneas que$ pueden ser tanto las de una vida como las de una obra literaria o de arte, las de una sociedad, según tal sistema de coordenadas elegido (Deleuze y Guattari, 2010, p.206).

Hecha esta aclaración sobre la forma como se emprende la lectura de EI último pecado, puede iniciarse la reflexión de la siguiente manera:

La novela de Martínez, quien fuera excomulgado por esta pieza literaria y perseguido — casi apedreado—, nos trae la historia de César, un joven estudiante que se encuentra residiendo en Bogotá, lugar de refugio y de venganza para sus penas de amor; traicionado por Laura, quien se ha entregado a otro hombre, estando comprometida con nuestro personaje. Allí, en la fría y bulliciosa capital, César encontrará la posibilidad para la apertura hacia un romance 'inusual', pues atraerá la atención y los afectos de Mario, pobre y bello adolescente, quien además delata su fuerte parecido físico con la 'traicionera e infiel' Laura. 
César, hombre de lecturas y espíritu convocado por el arte; de finos modales, seductores, profundos y atractivos ojos negros, feminófobo — a razón de la traición de Laura - no podrá, además, soportar la tentación que representa Ana Beturini, artista del arte dramático, quien rompe toda regla social, para acercarse al joven galán y vivirá una intensa experiencia que acarreará la reconciliación con Laura y con todo el pasado que pretendió dejar atrás. Historia que concluye con un cierre de ciclón, en el que César correrá, abandonando la línea flexible hacia la cual se había precipitado por la ruptura con Laura: quemará libros, romperá cuadros y esculturas tentadoras y, tal vez, por los efectos milagrosos de la oración de su madre, se reinsertará en las filas sociales, pretendidamente abandonadas.

Si examinamos esta breve pieza literaria del repertorio santandereano, podríamos ver que esta novela cumple con el encadenamiento que señala Deleuze para el género de novela corta: ¿qué ha pasado? (como modalidad o expresión), pues en efecto, sabemos que algo ha pasado, acontecido, percibimos el paso de ese algo, pero permanecerá 'incognoscible'. El secreto no nos es revelado y permanece oculto e inalterable, pero sí presentido; también alejado de la escritura, no podrá ser escribible, pero sí experimentable. Veamos, para el caso de nuestra novela, cómo manifiesta esta idea de: ¿qué ha pasado?:

Cuando estuvieron solos, César no se atrevía a pronunciar ni una sola sílaba. Una timidez casi trágica le acometía al encontrarse solo, aun cuando fuera en poder de la más modesta obrerilla. Le parecía que todo habría de avergonzarlo en aquel momento fatal, y sólo cuando vio a la Beturini arrojar sobre una gran silla Luis XV sus vestidos intensamente perfumados, se resolvió a afrontar todo lo que viniera después, tímido, tembloroso, apesadumbrado, como quien cierra los ojos para arrojarse a un charco profundo y amenazador. César salió hastiado de allí (Martínez, en España, Silva y Palencia, 2010, p.212).

En efecto, somos informados del ingreso de César y la Beturini a una pobre y lóbrega habitación de alquiler, de un destartalado Hotel de Transeúntes —nótese aquí el nombre del hotel, pieza clave para la interpretación — suponemos que algo debió pasar entre los personajes, algo más allá del encuentro entre los cuerpos y que ese algo ignorado fue la causa para poner fin a la 'fuga' de César, de la línea dura de la vida de César y para su retorno definitivo a ella, pues sabemos, ahora, que su destino será volver con Laura, perdonarla, casarse con ella e iniciar su vida definitiva, que tendrá, como bien apunta Deleuze, 'futuro pero no devenir'.

De otro lado, la apertura «in media res», técnica muy tradicional del arte narrativo moderno, nos sitúa justo en el medio de la ruptura de una vida, de una línea de vida que seguía las normas sociales de comportamiento, con apego, sin cuestionamientos y en la cual todo se haya previa y claramente definido, ubicado. La imagen percepto-visual con la que se abre la novela es lo suficientemente explícita y creemos no requiere de mayor explicación: 


\begin{abstract}
César abrió de par en par la ventanilla que daba sobre la avenida.
Aquél espectáculo de animación le pareció soberbio. Las largas filas de bombillas que colgaban de los árboles como frutos rojos y extraños [quizá ustedes, como yo, ya hayan hecho la asociación con el fruto delárbol prohibido del paraíso, el de las tentadoras y pecaminosas manzanas], la confusión del ómnibus, autos y tranvías que cruzaban las calles siniestramente, las lentas parejas de enamorados que curioseaban las vitrinas como fútil pretexto de sus citas, los gritos destemplados y monocordes de los gamines que volaban de transeúnte en transeúnte para ofrecerle Gil Blas, El Espectador, El Diario Nacional, mentas, almendras, caramelos, cigarrillos y chocolate, todo ese ambiente de populoso cosmopolitismo que hace deliciosa a Bogotá en las primeras horas de la noche, lo trastornaba casi (196).
\end{abstract}

Primeras manifestaciones de la línea flexible ubicada, justamente, más allá de su cerrado recinto y que provoca e incita al personaje; pero que simultáneamente trastorna. Línea flexible que deberá leerse como el espacio de la no norma, o de las otras normas, aquellas en las que se hace posible que sea la mujer la que declare su amor a un hombre, que le invite e incite a estar con él, quien le proponga y lleve, casi de la mano, a César, por los caminos de los encuentros espontáneos y no comprometidos para las fugaces relaciones de los enamorados; aquellas en las que se puede ser y expresar, pasando por encima de la rigurosa normatividad, propia de la línea dura en la cual ha sido formado el protagonista y que desea abandonar por un estímulo inauténtico: su deseo de venganza.

El retorno, luego de esta experiencia de ruptura, de salida de la línea dura hacia la línea flexible, luego de la experiencia de confrontación, por la confrontación con la otra realidad, al yo auténtico, el yo que reconocerá que su vida no está en la flexibilidad del vivir y sí en la rigidez instaurada por el grupo. Por ello, los recuerdos infantiles y felices del personaje lo han de llevar y nos han de permitir leer en ellos y a través de ellos el mundo ordenado, que como sustancia anquilosada en su pasado y en su cuerpo no le permitirán desprenderse. Ocurre, así, una re-edipización de César, la cual se expresa en una búsqueda de su pasado, para hallar en él el sólido fundamento de una vida segmentada y afirmada en la dureza de lo socialmente aceptado.

Precisamente en Kafka. Por una literatura menor afirma Deleuze y Guattari: "Uno se re-edipiza, no por culpabilidad sino por cansancio, por falta de invención, por imprudencia ante lo que se ha desencadenado, por foto, por policía: las potencias diabólicas de la lejanía" (1978, p. 52). No es, por lo tanto, un problema subjetivo de mal uso de la razón, ni de alienación, sino de las condiciones de la vida que reducen sus posibilidades y hace que se encuentre en la solidez del pasado la fuerza de la permanencia en el presente. 
Por ello, el lector descubrirá en la organización de las secuencias la alternancia entre presente-pasado; entre presente e intento de abandono total del personaje en la línea flexible, representada por la Beturini, por Mario y por el cosmopolita mundo exterior, por el sistema de controles narrativos impuestos en el relato: interrupciones constantes del mundo pasado; llamadas telefónicas e invitaciones de retorno a la normalidad, apariciones justas y anticipatorias del momento en el que el personaje parece derrotado por la fuerza de atracción de esa otra experiencia y vivencia del mundo, en el que las normas se hayan relajadas; la fuerza de la oración maternal y el poder del milagro pedido por la madre: "Se encerró en su habitación, después de despedirse secamente ${ }^{4}$ de la Beturini, y sintió como enormes deseos de llorar" (Martínez en España, Silva y Palencia, 2010, p. 213).

\begin{abstract}
Abandonaría la amistad con Mario, odiaría a la Beturini y, como Huysman, se iría a vivir frente a una capilla católica, en donde pudiera muy de mañanita, saltar de su lecho a la iglesia, en donde, cuando el pecado lo acometiera, encontrara al confesor listo a perdonarlo, en donde pudiera oír a sus anchas y con religioso cuidado, el ruido fresco, el ruido sonoro y ágil de las campanas que tanto amaba él (213).
\end{abstract}

Lo que tenemos en El último pecado es, entonces, la regresión a los segmentos más duros de la línea de segmentaridad molar, a la línea de corte y a la de los mirones de corto alcance, en la que nada cambia. La línea de fuga es truncada por la necesidad de rehacer las condiciones de una vida en la que existan parámetros claros para medir, determinar y fijar los segmentos de lo socialmente exigido. Como Deleuze plantea:

Las líneas de fuga son inmanentes al campo social. La segmentaridad flexible no cesa de deshacer las concreciones de la dura, pero reconstituye a su nivel todo lo que deshace, micro-Edipos, micro formaciones de poder, microfascismos. La línea de fuga hace explotar las dos series segmentarias, pero también es capaz de lo peor, de rebotar sobre la pared, de recaer en un agujero negro, de encaminarse hacia la gran regresión, y de rehacer los segmentos más duros al azar de sus rodeos (Deleuze y Guattari, 2010, p. 209).

Comprendemos, de esta manera, cómo al protagonista de El último pecado la vida le ofreció la posibilidad de desterritorialización, pero su edipo, la cultura, etc. fueron más fuertes y por ello se reterritorializa, buscando los segmentos más duros de su recaída en el agujero negro. También el recuerdo de la infancia actuó como supresor del deseo impidiéndole caer nuevamente en "el pecado" (que hubiese podido ser el acontecimiento de ruptura, de fragmentación de la línea dura de su vida). Ahora, arrepentido, y como en el mito del hijo pródigo, se reincorpora a la máquina social en su función precisamente establecida.

\footnotetext{
${ }^{4}$ Subrayado propio.
} 
Finalmente, podemos concluir que este esquizoanálisis muestra cómo, desde la propuesta deleuziana, la novela santandereana El último pecado, debe pensarse como manifestación del género corto para el departamento, pero muestra aún con más razón que Deleuze no sólo aporta una precisa y ajustada conceptualización del género, una tipología para el mismo, sino que responde a una necesidad práctica de la puesta en escena y diálogo de la teoría con la obra individual y que contribuye con argumentos muy sólidos a la reflexión e identificación de las mismas — las novelas cortas - siguiendo y acogiendo su compleja propuesta filosófica para la literatura, en particular para el género del cual nos hemos ocupado en este trabajo investigativo $\Phi$

\section{REFERENCIAS}

Deleuze, G. (1998). Lógica del sentido. Barcelona: Paidós.

Deleuze, G. y Guattari, F. (1978). Kafka. Por una literatura menor. México: Era.

Deleuze, G. y Guattari, F. (2010). Mil mesetas. Valencia: Pre-Textos.

España, G.; Silva, A. y Palencia, M. (2010). Novelas santandereanas del siglo XX, Vol. 4. Bucaramanga: Ediciones UIS.

Forster, E. M. (1983). Aspectos de la novela. Madrid: Editorial Debate.

Pabst, W. (1972). La novela corta en la teoría y en la creación literaria. Notas para una historia de su antinomia en las literaturas románicas. Madrid: Gredos.

Lukács, G. (1985). El alma y las formas. México: Grijalbo.

Lukács, G. (1985). Teoría de la Novela. México: Grijalbo.

Pavel, T. (2005). Representar la existencia. El pensamiento de la novela. Barcelona: Crítica.

Spang, K. (1993). Géneros literarios. Madrid: Síntesis.

Taylor, Ch. (1996). Fuentes del yo. La construcción de la identidad moderna. Barcelona: Paidós. 